\title{
Os trabalhadores da farinhada e a casa de farinha como lugar de memória
}

\author{
Francisco Evandro de Araújo*
}

\author{
Palavras-chave: \\ Trabalhadores da Farinhada \\ Casa de Farinha \\ "Lugar de Memória"
}

Keywords:

Meal workers

Flour house

"Place of memory"

\begin{abstract}
Resumo: O presente artigo tem por objetivo demonstrar de forma sucinta as características materiais deste ambiente/lugar e as relações construídas em torno das ferramentas que compõem o todo do engenho da farinha. Tendo como foco a análise dos retalhos de memórias e a observação empírica destes "museus a céu aberto" procuramos problematizar a relação entre aspectos materiais e imateriais forjada no contato corpo/ferramentas que se complementam num processo de reciprocidade entre o animado e o inanimado ressignificado a cada uso. De certa forma direcionamos nosso olhar para uma atividade de subsistência que resistiu ao longo do tempo, que com suas mudanças e permanências chegou até nossos dias. Jogamos luz no imprescindível papel histórico da experiência, do "saber-fazer" dos mestres da farinhada no cotidiano de suas atividades, no envolvimento entre pessoas e coisas que juntos forjam, no amalgama desta relação, o processo histórico.
\end{abstract}

\begin{abstract}
The purpose of this article is to demonstrate succinctly the material characteristics of this environment / place and the relationships built around the tools that make up the whole of flour mill. Focusing on the analysis of the memory fragments and the empirical observation of these "open-air museums" we try to problematize the relation between material and immaterial aspects forged in the contact body / tools that complement each other in a process of reciprocity between the animate and the inanimate re-signified Each use. In a way, we turn our gaze to a subsistence activity that has endured over time, which with its changes and permanences has reached our time. We throw light on the essential historical role of experience, the "know-how" of the masters of farinha in the daily life of their activities, the involvement of people and things that together, in the amalgam of this relation, forge the historical process.
\end{abstract}

Recebido em 31 de outubro de 2016. Aprovado em 06 de dezembro de 2016.

\section{Introdução}

O que é uma casa de farinha? Os pouco informados se apressarão em dizer que é um simples espaço onde se faz farinha e que suas características físicas e o modo como se faz farinha, nas chamadas farinhadas, ainda é marcado por técnicas e ferramentas rudimentares presentes nesses locais desde o período colonial quando estas eram usadas por indígenas e desbravadores. Ora, rotular a casa de farinha como mero espaço concreto e as farinhadas como meros resquícios das práticas folclóricas é não atentar para as significativas relações que se desenrolam no dia a dia de uma farinhada. Entre os anos 1960 e 1970, esses espaços representavam o lugar onde se produzia, em certos períodos do ano agosto a novembro -, muitos alimentos derivados da mandioca: farinha e goma com que se faziam beijus e tapiocas de forno e, como tudo que é histórico, desde então passou por significativas mudanças; porém, ainda comporta - no decorrer das últimas décadas - permanências peculiares. Mas não são as mudanças e as permanências, exatamente, que formam a matéria-prima da história no tempo?

A casa de farinha é o que podemos chamar de "lugar de memória" no cotidiano dos farinheiros e onde a relação entre as coisas e os homens vai se moldando na prática e nas maneiras de usar ferramentas, estas que, ao mesmo tempo em que são marcadas pelo uso humano, também delimitam a ação do homem que tende a se adaptar, "conscientemente ou não" à estrutura do objeto, já que é

[...] na interação com a materialidade as capacidades de atuação não se limitam exclusivamente aos atores humanos. Também as coisas são dotadas de animação, também elas exercem força motriz, também elas atuam socialmente, conformando um quadro de referências, possibilidades e limites ao agente humano, independente de este ter consciência disso ou não. Longe de ser passivamente estruturada pelo homem, a materialidade, pela sua própria fisicidade, age como estruturante da ação humana, e a 
propriedade de agir, a aptidão a operar, antes reservada ao ser humano, estendese agora à cultura material, sugerindo uma articulação, e por que não dizer, uma coexistência mais simétricas entre as várias dimensões da realidade. (REDE, 2012, p. 145).

Lugares de memória, pois os homens das farinhadas trazem marcas, às vezes indeléveis, na lembrança e no próprio corpo que também podemos chamar de uma ferramenta importante nesse processo produtivo. Vejamos o que diz, em depoimento, o senhor Francisco Otávio:

Taqui, isso aqui nos meu dedo não foi outra coisa não, foi a tarisca. $\mathrm{Na}$ época, eu tinha uns dezoito ano e papai foi fazer uma farinhada. Papai sempre fazia farinhada em agosto, depois do inverno. Aí eu fui inventar de cevar a mandioca. Cevar é relar [triturar] a mandioca. Num discuidim de nada, a bicha [caititu ${ }^{1}$ quase come meus dedo! (TAVARES, 2009).

A fala do senhor Francisco deixa clara essa tensão e exigência de cuidados na hora de manusear uma das ferramentas da casa de farinha que somente a experiência de muitos anos de trabalho com elas pode livrá-lo do risco de acidente. É o "saber-fazer" forjado na prática que leva o mestre da farinha a atuar com segurança no uso desse objeto e outros que conheceremos mais adiante.

A casa de farinha é, também, o que podemos chamar de "objeto biográfico", aquele com o qual podemos nos identificar, pois elucidam a memória através de sua materialidade, trazendo à tona experiências, impressões, sentimentos, sonhos e subjetividades.

Os objetos biográficos são construções do mundo material sobre as quais são projetadas experiências de vida do seu possuidor. Como fonte de descobertas, o objeto biográfico ancora memórias e representações. [...] pessoas e coisas não existem de forma separada. Os objetos biográficos contemplam significados simbólicos e idiossincráticos: "contam" a história de seus donos. (ALMEIDA; AMORIM; BARBOSA, p. 102).

Além de ser "objeto biográfico", a fábrica das farinhadas comporta em seu interior uma gama de ferramentas que ajudam a realimentar a memória do espaço que um dia foi ou continua sendo importante parte da história da vida de muitos produtores de farinha. Tais ferramentas símbolos da cultura material destas casas estão intimamente ligadas ao passado desses homens e dessas mulheres de forma que seria quase impossível se reconstruir uma história destes espaços sem considerar o relevante papel material e, ao mesmo tempo, imaterial que tais coisas representaram e ainda representam em alguns contextos. Ulpiano Bezerra de Meneses (1983, p. 107) afirma que: "[...] cindir cultura material e cultura não material é ignorar a ubiquidade das coisas materiais, que penetram todos os poros da ação humana e todas as suas circunstâncias".

\section{História e Cultura Material}

As relações entre história e cultura material nem sempre foram amigáveis. De um lado, os historiadores sempre superestimaram as fontes escritas, e deixaram em segundo plano as coisas materiais. Quando se utilizavam destas fontes, eles se restringiam à sua fisicidade em si, deixando de lado os aspectos subjetivos subjacentes a todo objeto material, pois o objeto não existe em si. É na interação cotidiana que matéria e sociedade se constroem (REDE, 2012; MENESES, 1983). Por outro lado, a Arqueologia, que tem nas coisas materiais em si seu objeto de escrutínio, catalogava e criava séries de objetos sem considerar contextos mais específicos como a interação desses objetos com o meio social em que foi produzido, procedimentos estes que apenas mudaram com o advento da New Archaeology na segunda metade do século XX (REDE, 2012).

Com a história os primeiros estudos, considerando-se a cultura material, também aparecem sob o apelo de revisão teóricometodológico da Nouvelle histoire e dos Annales; porém, sem muito impacto na forma e no modo de refletir a relação entre dimensões materiais e a organização social de modo que apenas no final do século XX é que a cultura material se torna objeto definitivo das produções historiográficas. $\mathrm{O}$ viés histórico para o uso da cultura material 
(REDE, 2012) pode ser encontrado em um estudo de Meneses (1983, p. 112), no qual menciona que: "[...] por cultura material, poderíamos entender aquele segmento do meio físico que é socialmente apropriado pelo homem". O autor enfatiza que a relação entre material e sociedade não se concretiza em uma relação unilateral, porque deve ser entendida como "produto e vetor das reações sociais" (MENESES, 1983, p. 113). É “[...] produto porque resulta da ação humana [...], vetor porque constitui um suporte e condutor concretos para a efetivação das relações entre os homens" (REDE, 2012, p. 147).

Daqui em diante, nós nos deteremos a descrever e analisar os diversos espaços da casa de farinha, a utilidade das diversas ferramentas e os espaços que compõem seu interior. Os tanques de peneirar, de tirar goma, de guardar farinha torrada, o caititu, (conhecido também como tarisca ou rodete, ferramenta de triturar a mandioca já pronta), além da prensa para retirar o excesso de umidade da massa antes de ir ao forno. Todos esses são elementos essenciais no espaço deste engenho. Mostraremos, ainda, as transformações pelas quais passaram algumas destas ferramentas como o uso da prensa com fuso de madeira e, posteriormente, a adoção da prensa com fuso de ferro tendo facilitado a prensagem da massa, tornando-a mais enxuta. Conheceremos, também, o forno, que é um dos espaços muito importantes da casa, pois dele sai a farinha pronta para o consumo. Por outro lado, lançaremos atenção aos profissionais que faziam da casa de farinha um espaço vivo, humanizado. Como os profissionais do forno, os torradores, viam este espaço e como resistiam ao calor emitido nos dias de farinhada? O que ficou no imaginário daqueles que tanto se esforçavam para fazer uma boa farinha? Como a profissional da goma, a tiradora de goma, resistia tanto tempo de pé enquanto obrava o "milagre" da extração desse polvilho com o qual se faziam as tapiocas de forno no final da farinhada?

Nos anos de 1970, a casa de farinha seguia certo padrão físico estrutural no município de Itapiúna, ${ }^{2}$ pelo menos naquelas instaladas em propriedades de fazendeiros que possuíam maior poder aquisitivo, como as do Senhor Valdemar
Antunes, grande comerciante, fazendeiro e dono de casas de farinha nas localidades do Touro e Lagoa do Mato, a do Senhor João Soares na então comunidade de Várzea das Bestas - atual Barra Nova - também fazendeiro e produtor de farinha, a de propriedade de Seu Raimundo Rosa na comunidade de Marrecas, a do Seu Brasilite na localidade de Nova Olinda, a do fazendeiro Oscar Donana na comunidade de Cajuás, na comunidade de Carnaubinha (hoje submergida pelas águas do Açude Castro - no período, havia o aviamento do senhor Antônio Costa), a do senhor Antônio, na comunidade da Reforma. Ao todo, em Itapiúna havia em média 45 casas de farinha, entre as com boa estrutura e as menos equipadas. Mas observamos que, em 1975, ainda havia em Itapiúna aviamentos com tecnologias da década de 1960. Por exemplo, a casa de farinha de propriedade de seu Luiz Frazão, na localidade de Barra dos Frazões, usou a roda até o início dos anos 1980, quando conseguiram comprar um motor a diesel - a energia ainda não tinha chegado por lá. Usavam-se lampiões a gás ou lamparinas para iluminar as noites de farinhada que, às vezes, adentravam na madrugada.

Havia, também, as casas com menor infraestrutura que pertenciam àqueles proprietários de menor poder aquisitivo. As casas com melhor infraestrutura eram construídas em modelo chalé com no mínimo um quarto e um grande galpão coberto com telhas de barro batido, produzidas em olarias $^{3}$ artesanais. Estas casas de farinha, além da infraestrutura necessária à produção de farinha e seus derivados, ainda possuíam um cômodo onde os produtores arrendatários do espaço poderiam ir guardando a farinha enquanto o processo da produção estava acontecendo, processo que, em algumas casas, levava em média entre três e sete dias por produtor. Esse quarto possuía dupla função: servia para hospedar alguns profissionais da farinhada, o próprio dono da arranca, o forneiro que tinha de "pegar com escuro"4 e a tiradora de goma que precisava lavar a massa muito cedo para ser prensada e, depois, levada ao forno que, de madrugada, já havia sido aceso pelo forneiro. Outra função do quarto era guardar a farinha torrada acondicionada em sacos de pano ou de plástico, até 
o fim da farinhada, quando o dono a transportaria para sua casa em lombos de jumentos e burros, principais meios de transporte da mandioca para a casa de farinha e da farinhada para a casa do proprietário. Cabe ressaltarmos que diz Dona Didi: "eu mais esse meu irmão, nóis saimo foi de rede pronta. Dormia lá. Só vinha no fim de semana" (SANTOS, 2009b). Em outro depoimento, fica clara a importância do quarto em uma casa de farinha:

Eu dormia na casa de farinha mermo! Dormia na casa de farinha! $\mathrm{Na}$ casa de farinha, dormia só eu e o prenseiro. Nóis dormia lá, pro mode pegar cedo, né? Dormindo em casa, a pessoa perdia a hora de pegar. O prenseiro botava uma prensa enxuta ali e outra na prensa, e nóis começava a arrochar. (LIMA, 2009).

Vejamos que as marcas do cotidiano desses profissionais da farinha se encontram de forma indelével nas memórias de homens e mulheres que, de uma forma ou de outra, têm a casa de farinha como um lugar onde passaram uma parte das suas vidas, onde produziram para a subsistência da família.

\section{Tirando a goma}

O galpão sustentado por várias colunas era o espaço onde se encontravam os tanques em um número de mais ou menos cinco, dois para tirar goma - quando a casa era de melhor infraestrutura - um para peneirar a massa prensada e, em outro se aparava a massa após ser cevada pelo caititu e ainda um grande ou dois pequenos - dependendo da estrutura da casa - para esfriar a farinha após sair do forno antes de ser ensacada, este geralmente se localiza anexado ao forno. Ainda havia algumas casas que possuíam dois tanques embaixo da prensa para aproveitar um pouquinho de goma que assentava da manipueira ${ }^{5}$ escorrida na prensa, apesar de ser uma goma de pouca qualidade, suja.

Estes tanques, pelo que pude observar em casas já abandonadas e nas que ainda resistem, têm tamanho médio, de aproximadamente 1 a $4 \mathrm{~m}^{3}$ dependendo das condições financeiras do dono da casa de farinha. A quantidade de tanques era muito importante neste espaço, pois agilizava o processo de fabricação dos derivados da mandioca. Dona Maria Luiza Martins dos Santos nos dá uma dica da sua relevância:

Só trabalho mais tirando goma. Meio dia, raspando; de tarde, tirando goma. Quando termino de tirar a goma prá deixar assentar, prá tira outra né, lá vou prá mandioca. Passa o dia, passa o dia! A gente só tira um tanque, assim [...] logo assim nos primeiro dia, a gente só tira um tanque. Aonde tem mais tanque, a gente tira mais. (SANTOS, 2009b).

"A gente só tira um tanque" - a expressão usada por Dona Maria Luiza - pode nos fazer perguntar se ela está falando das farinhadas dos anos 1970 ou se reporta às que ela continuou a fazer após esses anos. O que podemos concluir é que passado e presente se confundem quando a atividade que praticamos sofre mudanças; mas, as permanências estão sempre presentes na memória. E será que isso torna a fala de Maria Luiza menos importante como fonte oral para a história? Nada pode apagar a verdade que se encontra em sua memória e na de muitos que tiveram sua história de vida permeada por esse fazer que está impregnado de significados na memória coletiva dessa comunidade de destino (MEIHY, 2002). Como afirma o próprio Meihy (2002, p. 63): “[...]'comunidade de destino' é o resultado de uma experiência que qualifica um grupo dando-lhe princípios que orientam suas atitudes de maneira a configurar uma coletividade com base identitária".

Em todos os depoimentos de tiradoras de goma, é consenso esta afirmação: "tem que ter cabeça boa” expressão que tem grande significado para quem pratica essa arte. Tirar goma não é apenas um ato físico-motor, é sim o resultado de anos e anos de experiência adquirida desde a infância de uma prática que não pode ser medida metricamente, no entanto, pode ser sentida quando nos fazemos ouvintes atentos e observadores sensíveis.

Tirar goma tem um segredo, [...] porque a goma, ela só rende se a pessoa tiver a cabeça boa! Tem gente que tira, mas não tem rendimento. Cabeça boa 
é render a goma! É render a goma que a pessoa tira, que as vez tem gente que tira. Tira, enche um tanque. Mas num rende a goma. Num rende! (SANTOS, 2009b).

Esse segredo seria a própria experiência? Ou seria o resultado de superstições de que são acusados os farinheiros pelos que ainda insistem em afirmar que a produção de farinha foi rodeada de aspectos folclóricos? Experiência ou superstição folclórica não importa, o que se sabe é que essa subjetividade sempre esteve presente no concreto da vida dos farinheiros dessas bandas do Nordeste. E no Ceará não foi diferente. E bem se sabe que a história é feita do amalgama dessas duas realidades a concreta, supostamente objetiva e a imaterial por muitos criticada como disforme e subjetiva.

Até mesmo entre os homens se fala desse "segredo" ou habilidade das tiradoras de goma, como que, em se fazendo parte do dia a dia dessas mulheres, - tirar goma sempre foi uma atividade típica de mulheres - também se tome conhecimento da forma como elas próprias se autovalorizavam. Vejamos o que diz senhor Brasilite:

Tinha muiér que tirava goma porque tinha cabeça boa. Diz ela que, tirando goma tendo a cabeça boa, a goma assenta bem assentadinha. Parece que é sorte, né? Aí aquela goma assenta bem assentadinha. E a que tinha a cabeça baldeada, aí aquela goma virava mais era borra. (CASTELO, 2009).

Sobre o processo de tirar goma, temos uma descrição feita por dona Zélia, experiente tiradora de goma desde jovem:

Tirar goma? Eu achava era bom, aquilo ali. Depois daquela passada no[...] que chama tarisca, né? No cocho, né? No cocho. Aí, daí agente pega ela. Passa num pano, né? Numa cordinha. Numa redinha. Aí, a gente pega um pano fino forte, né? Pano fino forte, arma a redinha, né? Entre uma furquia ${ }^{6} \mathrm{e}$ outra no aviamento. E, daí, a gente pega aquela massa com manipueira e tudo, e esfrega no pano. E a manipueira desce, né? Vai aparando no cocho, ai vai aparando. Aí, depois que agente para, deixa assentar. Aí, quando assenta a manipueira, fica bem fininha, o líquido, né? Fica como uma aguazinha limpa. Tira fora e a goma fica embaixo. A tal goma fresca, né? É, ali, a gente apreende esses torrãozão. Bota prá vasilha. E, daí, bota pá secar, né? (SANTOS, 2009).

No sentido de se autovalorizar - "eu achava era bom" - é que muitas dessas profissionais acabam omitindo certas informações que são cruciais para se caracterizar uma atividade que aparentemente parece fácil, mas que, de certa forma, impunha certo grau de dificuldade a quem praticava. Imagine passar o dia inteiro em pé, naquele movimento de sobe e desce para pegar a massa cevada, colocar na rede de tirar goma, espremer com força após ter jogado várias cuias ${ }^{7}$ d'água para lavar? Dona Maria Luiza nos dá uma ideia do resultado desses movimentos repetitivos: "Nunca cansei não, tanto fazia para tirar como para raspa. Para raspar mandioca eu acho mió de que tirar goma. Taqui, esses meus dedo é aleijado, né? De outra coisa não. É de espremer!" (SANTOS, 2009b, grifos nossos). Nunca cansou, mas ficou aleijada dos dedos de uma mão. Deixou clara a dureza de sua atividade, que exige muita força, habilidade e resistência.

Fora os segredos que cada uma das profissionais da goma guardam, temos uma descrição de Auguste de Saint-Hilaire falando que se usa uma espécie de rede: "A extremidade superior da rede é presa no soalho, a outra a um cabrestante; este gira e por esse meio estende a rede que, agindo sobre a polpa, obriga o resto da água a sair" (SAINTHILAIRE, 1936 apud AGUIAR, 1982, p. 73).

As casas de farinha e as farinhadas, com toda sua materialidade e subjetividade - como todo objeto da história -, sofreram mudanças importantes, nos anos 1970, que precisam ser problematizadas e analisadas dentro do seu contexto histórico próprio, não podendo ser postas no esquecimento por uma historiografia que ignora, principalmente, as mudanças ocorridas nestes espaços. Quais foram essas mudanças? Representaram muito no dia a dia dos farinheiros? Apesar das mudanças, como em tudo que é histórico, há muitas permanências. Elas têm muito a nos mostrar em termos materiais e precisamos ser capazes de interpretar os significados 
que toda materialidade desses espaços representava na vida de muitos produtores de farinha.

O observador do passado não precisa de seus olhos somente para usá-los sobre velhos e indecifráveis escritos. Ele também precisa abri-los bastante para o espetáculo do mundo material. Assim conseguirá construir, pouco a pouco, uma história tal como a sonhamos; uma história capaz de tomar o ser humano por inteiro, com as coisas que ele criou e que o comandam. (BLOCH, 2001, p. 118).

\section{O forno e o torrador}

Entre os elementos que compõem a infraestrutura da casa de farinha há um que podemos caracterizar como o que exige muita resistência no ato de usá-lo. $\mathrm{O}$ forno é de onde sai o produto final de uma farinhada: a farinha torrada. Mais do que uma tecnologia para torrar farinha, o forno é um espaço que carrega em si uma carga de significados que somente podemos compreender quando ouvimos aqueles que, dias e dias, meses e meses enfrentam a quentura e o calor da fornalha da casa de farinha.

Materialmente falando, o forno é um espaço arredondado com $1,10 \mathrm{~m}$ de altura. A parte superior onde se põe a massa para ser torrada tem em média $12 \mathrm{~m}$ de diâmetro, é formada por lajes de cimento postas sobre trilhos de ferro que ajudam o forno a se aquecer mais rapidamente. São trilhos descartados pela companhia ferroviária ou que eram adquiridos com responsáveis pelas ferrovias por alguma autoridade amiga do dono da futura casa de farinha. Havia, também, as casas em que as lajes de cimento eram colocadas em pequenas paredes de tijolo na parte interna do forno. Segundo relatos de torradores, os fornos com paredes de tijolos demoram a esquentar; mas, quando esquentam, permanecem assim por várias horas.

Manusear como forneiro exige muita habilidade: além do raio circunferencial ser grande - em algumas casas era de aproximadamente uns $12 \mathrm{~m}$ de circunferência, o que exige um rodo $^{8} \mathrm{com}$ um cabo muito comprido - a temperatura chega a atingir $50^{\circ} \mathrm{C}$ em certos períodos de um dia de farinhada. A boca do forno geralmente fica na parte externa da casa, o que ameniza um pouco. Mesmo assim, o forneiro precisa de muita resistência para suportar o calor. E é por isso que os forneiros preferem trabalhar começando de madrugada, ou seja, "acordando com escuro", muito cedo na linguagem do sertanejo, como citei anteriormente, até as 9 ou 10 horas, continuando no final da tarde, quando o impacto da temperatura é amenizado por uma menor temperatura neste turno. $\mathrm{O}$ peso do rodo e da farinha, a qual precisava ser mexida sem parar, exigiam do forneiro uma habilidade física extraordinária, "o suor pingava da cabeça aos pés, mas não podia parar", diz seu Francisco Otávio, produtor de farinha desde menino.

Nesta relação do corpo com o forno é que se dá a construção de significados que se subjetivam no cotidiano dos forneiros. Além disso, o uso do forno pode acabar por provocar doenças naqueles que lidam com ele durante muito tempo.

Eu mesmo quase pegava um ramo por causa da quentura do forno. Tive um grande dor de cabeça, o que me salvou foi a cachaça alemã. Senão, eu não sei o que podia ter acontecido comigo. Minha mulher ficou muito preocupada; mas, eu disse pra ela:, "larga de ser besta, mulher, vaso ruim não se quebra!”. (LIMA, 2009).

À semelhança do que Dona Maria Luiza falou, seu irmão Luiz dos Santos Lima também não assume diretamente a dureza do trabalho do forneiro. Seu autoelogio - "cabra só aguenta se tiver coragem" - tem um significado todo especial, pois demonstra satisfação na sua prática profissional, principalmente quando afirma: "Gostei!". Como se nada importasse a não ser a habilidade de um "cabra" de coragem que aguenta; resiste porque é homem. Muitas vezes, o elogio do "patrão" era um bom combustível para a autoestima desses profissionais, sejam torradores, tiradoras de goma, e até mesmo os cevadores atenciosos com os perigos da tarisca. Percebemos que coragem e força são requisitos para lidar com essa ferramenta da casa de farinha; nesse sentido, "[...] o universo material pode ser considerado parte da própria corporalidade, em 
uma síntese que, longe de ser estática, implica interação dinâmica entre corpo, espaço e objetos" (REDE, 2012, p. 141).

Mais do que um espaço material, o forno também é um lugar cheio de subjetividade. Mas, ao pesquisador menos atento à cultura material dos "fracos", passa despercebido e "consideram essas pequenas preocupações como abaixo da majestade de Clio" (BLOCH, 2001, p. 434). Por isso, acabam relegando ao esquecimento um tipo de vestígio material que, com certeza, ajudará o pesquisador interessado a dar sentido histórico a um espaço do qual se demorou a perceber, que " [...] não se tratava, como disseram alguns, de 'mesquinha agricultura de subsistência'. Nem tão pouco de homens 'decadentes e degenerados', como queriam outros. Mas de atores históricos responsáveis por competências [...]" (DEL PRIORE; VENÂNCIO, 2006, p. 48) sem as quais a complexa engrenagem do processo histórico estaria comprometida e até mesmo incompleta. E, com tal constatação, percebemos que omitir informações não é uma característica apenas da memória, mas uma estratégia de reconhecimento ou não, daquilo que interessa ao historiador, que inevitavelmente se envolve subjetivamente com seu objeto de estudo.

Questionando a nossa historiografia agrária, devemos e podemos indagar: por que um forno de casa de farinha seria menos importante do que uma fornalha de engenho? Que fontes seriam mais dignas de confiança do que os próprios relatos dos que envelheceram dedicando a vida a produzir para os mais abastados? Pois frequentemente apenas

[...] os velhos possuem ainda o manejo dos instrumentos cuja receita, transmitia-se de geração em geração. Se não tomarmos cuidado, eles não tardarão a levar consigo seus segredos nesse reino das sombras cujo acesso o mais zeloso pesquisador não poderia obter. (BLOCH, 2001, p. 108).

Quando se põe em evidência histórica um espaço aparentemente banal, como o forno de uma casa de farinhadas, está dando-se a oportunidade de se fazer justiça com aqueles que, utilizando-se dele, puderam produzir alimentos em uma época em que a farinha engrossava o caldo de muita gente, até mesmo os mais abastados; afinal, na história: "O dever da memória é o dever de fazer justiça pela lembrança ao outro" (RICOEUR apud DOSSE, 2004, p. 159).

\section{A prensa e o prenseiro}

Já pela metade dos anos 1970, muitas casas de farinha haviam sido abandonadas, o que se explica pela pressão demográfica e as inovações tecnológicas nas formas capitalistas de produzir que levaram o pequeno produtor, desprovido de financiamento governamental, a abandonar o campo. E isso provocou a uma drástica redução da produção de farinha de mandioca cultivada. Em Itapiúna, no ano de 1975, segundo dados do IBGE, dos 121 produtores de farinha de 1970, somente restavam quatro. Mas isso não invalida um estudo, mesmo de cunho local, que tenha como finalidade reconstruir esses espaços com o poder da escrita alimentada pelas memórias desses "personagens anônimos da história” (VAINFAS, 2002).

Compreender que a partir dos anos 1970 esses espaços sofreram uma decadência progressiva em termos quantitativos, apesar de ter havido, no município de Itapiúna, uma melhoria infraestrutural com a introdução do motor a diesel e, posteriormente, do motor elétrico, é uma responsabilidade que nos cabe enquanto estudiosos do passado, da história. Tais mudanças se deveram a um contexto nacional marcado pela concessão de subsídios governamentais ao trigo, aumento da urbanização, provocando a diminuição no consumo de farinha e a consequente diminuição desses estabelecimentos em escala nacional. E, é claro, tal mudança também afetou essa cultura em escala local já que "[...] a história local - de uma aldeia, de um município - está destinada a fazer compreender as ligações dessa pequena sociedade com o conjunto mais vasto em que inserida". (BLOCH, 2001, p. 203).

Já antes dos anos 1970, havia casas de farinha com motor a diesel, mas eram muito poucas. Uma boa parte ainda usava uma roda de madeira provida de duas manivelas e movimentada por dois homens, que acionava a tarisca para triturar a mandioca. A prensa, engrenagem formada por 
dois troncos verticais de madeira nobre, geralmente pau d'arco ou maçaranduba, e outro na horizontal com um orifício no centro por onde passa um fuso espiral que acocha a massa preso aos dois troncos verticais, também passou por mudanças no decorrer desta década. Até o início de 1960, usava-se uma prensa toda de madeira. De 1975 em diante, aboliu-se o fuso de madeira e se adotou o fuso de ferro. Tais mudanças foram positivas, $o$ fuso de madeira se tornava fraco depois de certo tempo de uso, e houve casos em que se quebrou durante uma prensada provocando prejuízos para o dono da casa de farinha e para o arrendatário, visto que este se obrigava a procurar imediatamente outro aviamento para terminar a farinhada. $\mathrm{O}$ fuso de ferro era mais resistente e aguentava mais acocho sem risco de se romper. E, para facilitar a prensagem o fuso de ferro, era sempre bem lubrificado com óleo queimado ou mesmo graxa. A falta de manutenção periódica nas ferramentas da casa foi causa de muitos prejuízos para donos e arrendatários. O prenseiro era um profissional que precisava ter, entre as suas habilidades, muita força, já que prensar a massa, principalmente em uma prensa com fuso de madeira, exigia "destreza" desse trabalhador da farinhada. Para essa função, estavam sempre prontos dois homens fortes dispostos a usar a força que a atividade exigia.

\section{A tarisca e o cevador}

Além da prensa, outra ferramenta vai passar por uma sensível mudança que, naquele momento, representará um avanço na forma de se triturar a mandioca. Até meados dos anos de 1960, usavase uma roda de no mínimo $2 \mathrm{~m}$ de raio que era movimentada, por dois homens, por meio de duas manivelas, conhecida como bolandeira, e acionava um rolo de madeira revestido de centenas de lâminas com dentes pontiagudos e muito afiados, denominada de tarisca. Podemos deduzir ser necessário dispensar certa força para fazer mover essa roda.

No outro lado, estava o cevador empurrando a mandioca contra esste rolo que deixava a mandioca totalmente triturada dentro de um tanque próprio para esse fim, que ficava sob a tarisca. Esta ferramenta cortante não sofreu modificações no decorrer dos séculos até hoje, mas tem várias denominações que variam de comunidade para comunidade. Entre os nomes que tal ferramenta recebia, podemos citar: tarisca, rodete, bola e caititu.

Vejamos o que Antônio José da Conceição nos fala sobre essa forma rústica de ralar a mandioca em algumas casas de farinha no Nordeste ainda nos anos de 1970: “[...] são raladas em cilindro de madeira provido de serrilhas, acionado por uma roda de madeira movida por homem, que se acopla ao mesmo por meio de uma correia de couro. Em alguns casos, pode existir um pequeno motor que aciona o cilindro ralador" (CONCEIÇÃO, 1987, p. 95).

As mudanças em escala local se universalizaram, ou seja, foram adotadas por todos os proprietários de aviamentos no início da segunda metade dos anos de 1970. Em 1975, todas as casas de farinha já cevavam sua mandioca com motor a diesel, mas a força humana continuou sendo a chave para movimentar a manivela que dava partida no motor. No entanto, em meados desta década, aconteceu uma nova mudança. A energia elétrica "chegou" às principais localidades produtoras de farinha: Nova Olinda, Barra dos Frazões, Touro, Cajuás, entre outras. E os proprietários adotaram o motor elétrico, menor e mais eficiente. A força humana, então, estava dispensada, pelo menos para triturar a mandioca.

O Cevador era um homem que, dentre outras habilidades, precisava ser muito atento ao que estava fazendo, pois a atividade que desempenhava exigia muita concentração, visto que a qualquer momento ele poderia se machucar. Casos de perda de partes dos dedos foram relatados. Isso acontecia devido à grande velocidade do caititu movido a óleo diesel. Devido à impossibilidade de parar subitamente a bola que rodava em alta velocidade, alguns cevadores tinham partes da mão amputadas.

\section{Considerações finais}

A casa de farinha era, nos anos de 1970, o espaço cujas ferramentas, mesmo rudimentares, já haviam passado por mudanças que facilitaram ou, 
pelo menos, transformaram a prática de alguns dos profissionais da farinhada. As tecnologias de prensar e cevar sofreram as mudanças mais significativas, exigindo novas habilidades dos operários da farinha. Por outro lado, as técnicas de torrar e tirar goma continuaram imóveis no tempo, sem exigirem novas habilidades para a sua prática; contudo, a extração da goma ainda permaneceu por alguns anos cercada de superstições - "tem que ter a cabeça boa!" - que as praticantes mais tradicionais ainda insistem em fazer valer. Isso faz parte da própria relação subjetiva entre os elementos materiais e os significados imateriais que foram se construindo em torno dos usos dos objetos e transformando a casa de farinha em "lugar de memória", onde o meio físico que é socialmente apropriado pelos seus trabalhadores se torna, também, "objeto biográfico" condutor de memórias e representações.

Como afirma Braudel (2005, p. 19): "Vida material são homens e coisas, coisas e homens". Entendo, também, que o processo histórico não ocorre apenas no âmbito dos grandes feitos; além disso, é preciso que se faça mostrar, torne conhecidas as práticas dos chamados pequenos, da produção em pequena escala; afinal, queiram ou não, a produção, de qualquer produto, por menor que seja, tanto sofre influências do grande mercado como influência este. Isso foi o que tentamos fazer ao iniciar esta pesquisa e escrever este material que, longe de ter demonstrado um estudo em definitivo, pretende ser uma perspectiva de estudo e mostrar caminhos que, como historiadores, ainda estamos pouco afeitos a seguir.

\section{Notas}

1 Cilindro dentado para triturar a mandioca.

2 Um dos municípios da Região do Maciço de Baturité, localizado a $110 \mathrm{~km}$ da capital, Fortaleza/CE e objeto da pesquisa realizada naquele momento.

3 Lugar onde se produziam telhas sem o uso de máquinas, mas à mão.

4 Bem "sedo", é como ainda se fala nos sertões do Nordeste.

5 Líquido com alto teor de ácido cianídrico altamente venenoso jogado fora em lugar longe de animais.
6 Porrete de madeira bifurcado na parte superior, onde se amarrava a rede de lavar mandioca ralada.

7 Uma das partes da cabaça, planta comum no Nordeste.

8 Ferramenta com que se mexe a farinha molhada no forno, até dar o ponto de consumo.

\section{Referências}

AGUIAR, P. Mandioca: pão do Brasil. Rio de Janeiro: Civilização Brasileira, 1982

ALMEIDA, J. R. de; AMORIM, M. A. B. V.; BARBOSA, X. de C. Performance e Objeto Biográfico: questões para a História Oral de Vida. Oralidades: Revista de História Oral, São Paulo, ano 1, n. 2, p. ?, jul./dez. 2007.

BLOCH, M. A terra e seus homens: Agricultura e vida rural nos séculos XVII e XVIII. Bauru: EDUSC, 2001.

BRAUDEL, F. As Estruturas do Cotidiano: O possível e o Impossível. In: Civilização Material, Econômica e Capitalismo Séculos XV XVIII. V. I. São Paulo: Martins Fontes, 2005. p.?

CASTELO, B. P. Entrevista realizada em sua residência. Nova Olinda, Itapiúna/CE, 24 fev. 2009.

CONCEIÇÃO, A. J. da. A mandioca. 3. ed. Nobel. São Paulo: 1987.

DEL PRIORE, M.; VENÂNCIO, R. Uma história da vida rural no Brasil. Rio de Janeiro: Ediouro, 2006.

DOSSE, F. História e Ciências Sociais. Bauru: EDUSC, 2004.

LIMA, L. dos S. Entrevista realizada em sua residência. Barra Nova, Itapiúna/CE, 25 mar. 2009.

MEIHY, J. C. S. B. Manual de História Oral. 4. ed. São Paulo: Edições Loiola, 2002.

MENESES, U. T. B. de. A cultura material no estudo das sociedades antigas. Revista de História - USP, São Paulo, n. 115, p. 103-117, jul./dez. 1983. 
REDE, M. História e cultura material. In: CARDOSO, C. F.; VAINFAS, R. (Org.) Novos Domínios da História. Rio de Janeiro: Elsevier; Campus, 2012. p. ?

RICOEUR, P. La mémoire, l'histoire, l'oubli. Paris: Seuil, 2000.

SAINT-HILAIRE, A. Segunda Viagem ao Interior do Brasil. São Paulo: Comp. Editoria Nacional, 1936.

SANTOS, A. Z. dos. Entrevista realizada em sua residência, Carnaubinha dos Padeiros, Itapiúna, CE, em 20 mar. 2009a.
SANTOS, M. L. M. dos. Entrevista realizada em sua residência, Barra Nova, Itapiúna, CE, em 21 mar. 2009b.

TAVARES, F. O. Entrevista realizada em sua residência. Bairro Vila Amorim, Itapiúna/CE, 23 fev. 2009.

VAINFAS, R. Os protagonistas Anônimos da História: Micro-história. Rio de Janeiro: Campus, 2002. 